\title{
A THUNDERSTORM IN TOWN
}

\author{
A Reminiscence : 1893
}

SHE wore a new 'terra-cotta' dress, And we stayed, because of the pelting storm, Within the hansom's dry recess, Though the horse had stopped; yea, motionless We sat on, snug and warm.

Then the downpour ceased, to my sharp sad pain And the glass that had screened our forms before Flew up, and out she sprang to her door:

I should have kissed her if the rain

Had lasted a minute more.

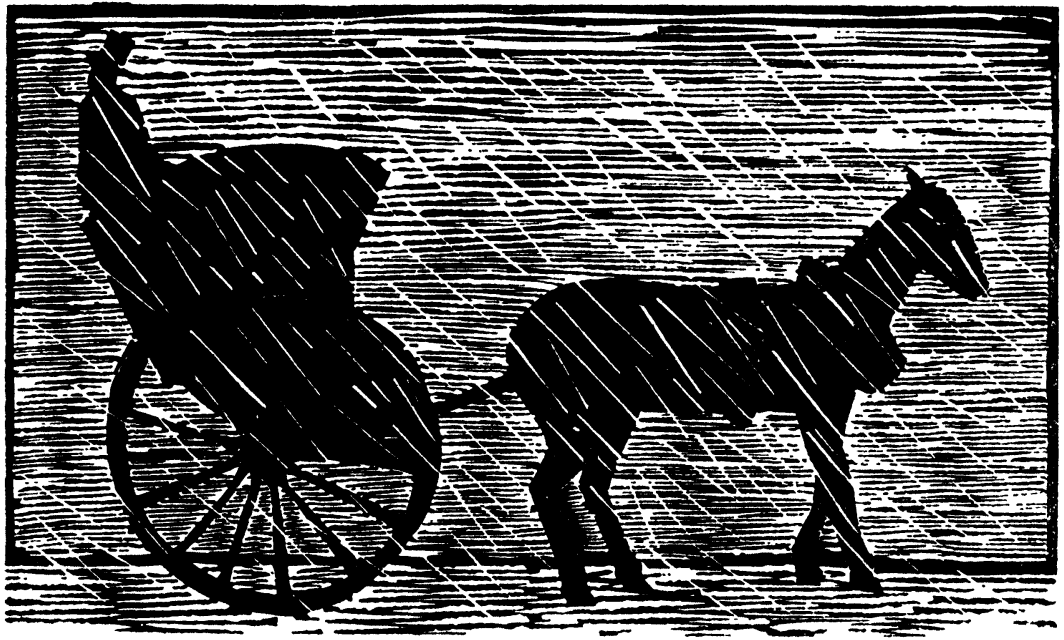

